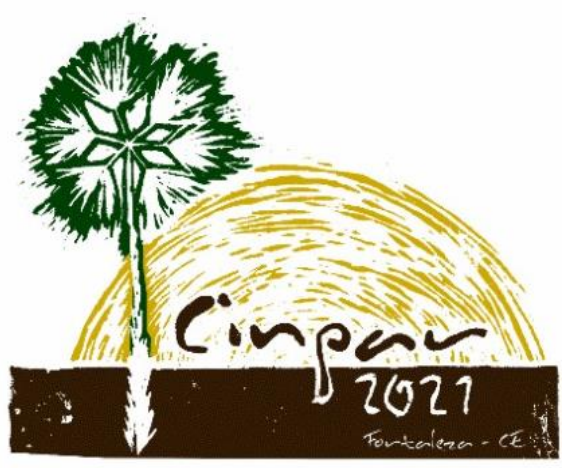

XVII Congresso Internacional sobre Patologia e Reabilitação das Construções

XVII Congreso Internacional sobre Patología y Rehabilitación de las Construcciones

XVII International Conference on Pathology and Constructions Rehabilitation

FORTALEZA (Brasil), 3 a 5 de junho de 2021 https://doi.org/10.4322/CINPAR.2021.101

\title{
Percepção de uma edificação pertencente ao patrimônio histórico e cultural por meio de inspeção, modelo de dano e depreciação - Teatro Nacional Cláudio Santoro
}

\section{Perception of a historical and cultural heritage building through inspection, damage model and depreciation - Teatro Nacional Cláudio Santoro}

\author{
Naiara PORTO ${ }^{1}$, Jõao PANTOJA², Iberê OLIVEIRA ${ }^{3}$ \\ 1 Universidade de Brasília, Brasília, Brasil, naiarag.porto@gmail.com \\ 2 Universidade de Brasília, Brasil, joaocpantoja@gmail.com \\ ${ }^{3}$ Universidade de Brasília, Brasília, Brasil, iberep@gmail.com
}

\begin{abstract}
Resumo: Entender o patrimônio histórico como um conjunto de bens, materiais ou naturais, que de alguma maneira fez parte de um momento de relevância na história de determinada sociedade ou comunidade, é o foco deste estudo. O Teatro Nacional Cláudio Santoro, situado na região central de Brasília, foi construído para ser o centro das atividades de cultura, porém, desde o início da sua construção, em 1960, até os dias atuais, o Teatro teve dificuldades na sua abertura e no seu funcionamento. Mesmo com os problemas que surgiram ao longo de seus mais de 50 anos de existência, relacionados ao uso e a falta de manutenção, atualmente o Teatro se apresenta como um sistema global em plenas condições de funcionamento, porém, com anomalias e adversidades de adaptação às necessidades e avanços conceituais que surgiram com o tempo. Tendo como objetivo a verificação da situação de três sistemas: mobiliário, estrutura e cobertura, inspeções visuais foram realizadas a fim de identificar as anomalias e patologias presentes, bem como atestar as condições de segurança e conservação do patrimônio, juntamente com uma análise de depreciação dos sistemas. O estudo utiliza a tabela GUT, por metodologia adaptada, cuja classificação determina a ordem de prioridade dos sistemas pelos danos verificados. De forma geral, a estrutura do Teatro se apresenta em boas condições, indicando apenas alguns locais pontuais em condições mais críticas. Porém, percebe-se que a maioria das patologias existentes ocorre devido à problemas de infiltrações nas fachadas e em juntas de dilatação da estrutura principal, afetando, não somente a parte estrutural da edificação, como também toda a parte estética e funcional, como o mobiliário. É entendido, portanto, que a revitalização de um patrimônio histórico consiste na reabilitação de seus sistemas e na sua refuncionalizacão, de forma que a preservação do patrimônio acompanhe as transformações do espaço urbano.
\end{abstract}

Palavras-chave: Patrimônio Histórico e Cultural; Patologias; Tabela GUT; Depreciação

\section{Introdução}

As peculiaridades da região, onde se demarcou os limites do Distrito Federal, eram inóspitas no que diz respeito ao solo e ao clima. A desertificação gradativa, já caminhava de forma explícita, trazendo dificuldades na ocupação da terra. Com o passar do tempo suas construções ganharam vidas e identidades próprias. Também começaram a sofrer os desgastes patrocinados pela idade e pelas intempéries. A partir de então, seus monumentos ficaram à mercê de suas administrações para conservação e manutenção. Isso acabou gerando uma desigualdade na condição física de alguns edifícios. 
Instituições ligadas à arquitetura, urbanismo e patrimônio, começaram a se preocupar com o estado de alguns edifícios e selecionaram o Teatro Nacional de Brasília para uma avaliação de patologias em todos os seus sistemas integrantes, neste trabalho, porém, só serão abordados a estrutura, a cobertura e o mobiliário.

Essa seleção baseou-se na condição de inoperabilidade do Teatro e por várias outras razões ligadas a degradação das edificações, depreciação do patrimônio, gerado pelo tombamento, cujo teor assumia uma postura e não permitir quaisquer intervenções no bem histórico.

Hoje, com uma parceira entre diversas organizações ligadas ao tema, incluindo o Laboratório de Reabilitação do Ambiente Construído (LabRAC), da UNB, está sendo possível desenvolver esta pesquisa, objetivando propor metodologia de recuperação e sistema de manutenção periódica para perenização do patrimônio considerado ícone da arquitetura e da cultura de nossa Nação.

\section{Patrimônio Histórico e Cultural}

A formação histórica e cultural em uma sociedade tem um forte vínculo com as formas de expressões advindas das mãos humanas. Considerando as obras arquitetônicas como conceitos de quem projeta, chegase ao entendimento que as edificações que têm valor - artístico, estético, social, cultural, religioso, científico, simbólico e outros - para uma sociedade e/ou comunidade, assumem um papel de grande importância na história. É neste momento, então, que se confere o título de patrimônio histórico e cultural a determinado bem móvel, imóvel ou natural.

No Brasil, o Art. 216 da Constituição Federal estabelece o conceito para patrimônio cultural brasileiro como:

"Art. 216. Constituem patrimônio cultural brasileiro os bens de natureza material e imaterial, tomados individualmente ou em conjunto, portadores de referência à identidade, à ação, à memória dos diferentes grupos formadores da sociedade brasileira, nos quais se incluem:

I - as formas de expressão;

II - os modos de criar, fazer e viver;

III - as criações científicas, artísticas e tecnológicas;

IV - as obras, objetos, documentos, edificações e demais espaços destinados às manifestações artísticoculturais;

V - os conjuntos urbanos e sítios de valor histórico, paisagístico, artístico, arqueológico, paleontológico, ecológico e científico.".

A conservação destes patrimônios é, portanto, instrumento de grande importância para preservar memórias e dar continuidade na história para futuras gerações. No viés da arquitetura e engenharia, a preservação do patrimônio histórico e cultural se torna um quesito urbano, sendo um ponto relevante na manutenção de vínculos com origens e identidades de cidades e, assim, de comunidades.

Dessa forma, visando a preservação de um patrimônio histórico e cultural, utiliza-se o tombamento como instrumento jurídico de reconhecimento e proteção de bens materiais, móveis ou imóveis, podendo ser feito pela administração federal, estadual e municipal ou em esfera mundial.

Se tratando de Brasília, o seu conjunto urbano foi reconhecido pela Unesco, em 1987, como Patrimônio Mundial e seu conjunto urbanístico-arquitetônico, construído a partir do plano piloto, inscrito no livro de Tombo Histórico pelo Iphan, em 1990.

Confere-se, então, uma grande importância ao conjunto urbanístico de Brasília, através de suas características monumental, residencial, bucólica, gregária e arquitetura inovadora, o que repercute na maior necessidade da sua preservação.

\subsection{Avaliação e Depreciação do Patrimônio}

$\mathrm{Na}$ avaliação de bens históricos e culturais, o que conduz a gestão do patrimônio é o bem coletivo, de toda uma sociedade. Refere-se ao levantamento de um conjunto de informações pertinentes e relevantes da história, economia, sociologia, política, arquitetura, engenharia, etc., em que cada um desses aspectos pode ou não estar correlacionado. 
O valor do patrimônio que, na maioria das vezes, exprime um sentido subjetivo e de difícil identificação, indica a razão pelo qual este bem se torna singular, ou seja, as variáveis formadoras do seu valor econômico (Júnior, 2019, p. 35).

Por esta motivo que a conservação e restauração se tornam condições de importância para perdurar o patrimônio, no decorrer do tempo, sem ou com o mínimo de alterações possíveis. Tendo em vista que o estado de conservação está diretamente ligado ao nível de depreciação de uma edificação.

No Brasil, ainda não há uma cultura centrada na manutenção de suas edificações, o que é um erro, pois a vida útil de uma construção está atrelada a seu uso. A utilização de manutenções preventiva e corretiva é uma ferramenta de suma importância para garantir a vida útil de projeto e, também, para poder estender essa vida útil.

\section{Método de Ross-Heidecke}

O método de Ross-Heidecke é utilizado para o cálculo da depreciação de bens patrimoniais imóveis, por meio da vida-útil estimada, idade real e o estado de conservação da edificação.

A depreciação é verificada nos sistemas componentes da edificação, como estrutura, hidráulica, cobertura, elétrica, fundação, etc. Já a idade da edificação resulta de coeficientes que podem ser potencializados pelo surgimento de patologias.

O fator de depreciação (FD) é calculado por:

$$
F D=[\alpha+(1-\alpha) \cdot c] \cdot V d
$$

Em que,

$F D=$ Fator de depreciação;

$c=$ Coeficiente Heidecke;

$\alpha=$ Parcela de depreciação pela idade real já decorrida segundo método de Ross;

$V d=$ Valor depreciável.

O coeficiente Heidecke está relacionado ao estado de conservação da edificação, conforme Quadro 1.

Quadro 1 - Coeficiente de depreciação física pelo estado de conservação da edificação

\begin{tabular}{|c|c|c|c|}
\hline Estado de Conservação & Classificação & Depreciação (\%) & Coeficiente de Heidecke (c) \\
\hline Nova & Ótimo & 0,00 & 0,0000 \\
\hline Entre nova e regular & Muito bom & 0,32 & 0,0032 \\
\hline Regular & Bom & 2,52 & 0,0252 \\
\hline Entre regular e reparos simples & Intermediário & 8,09 & 0,0809 \\
\hline Reparos simples & Regular & 18,10 & 0,1810 \\
\hline Entre reparos simples e importantes & Deficiente & 33,20 & 0,3320 \\
\hline Reparos importantes & Mau & 52,60 & 0,5260 \\
\hline Entre reparos importantes e edificações sem valor & Muito mau & 75,20 & 0,7520 \\
\hline Edificação sem valor & Sem valor & 100,00 & 1,0000 \\
\hline
\end{tabular}

A parcela de depreciação $(\alpha)$ é calculada pela idade real (IR), que vai do ano corrente ao ano de construção, e pela vida útil estimada (VUE).

$$
\alpha=\frac{1}{2}\left(\frac{I R}{V U E}+\frac{I R^{2}}{V U E^{2}}\right)
$$

\section{Tabela GUT}


A Tabela GUT é uma ferramenta utilizada para indicar anomalias e falhas detectadas em uma edificação, no momento da vistoria/inspeção, que viabiliza priorizar o dano pela sua gravidade, urgência e evolução. Ela foi criada por Kepner e Tregoe (ANO?) para ajudar na tomada de decisão por priorização de problemas.

A gravidade representa o impacto e a intensidade que o dano pode gerar com o tempo. A urgência determina o tempo necessário para repara o dano. A tendência demostra o potencial de crescimento do dano, ou seja, sua evolução do nível de criticidade.

O Quadro a seguir mostra a classificação, pontuação e critérios para cada elemento da Tabela GUT, por metodologia adaptada, que será utilizada no presente trabalho.

Quadro 2 - Classificação e pontuação dos critérios da Tabela GUT, metodologia adaptada

\begin{tabular}{|c|c|c|c|c|c|}
\hline Grau & Código & Peso & Gravidade & Urgência & Tendência \\
\hline Total & $\mathrm{T}$ & 10 & $\begin{array}{l}\text { Perda de vidas humanas, do meio } \\
\text { ambiente ou do próprio edifício }\end{array}$ & Evento em ocorrência & $\begin{array}{l}\text { Evolução } \\
\text { imediata }\end{array}$ \\
\hline Alto & $A$ & 8 & $\begin{array}{c}\text { Ferimento em pessoas, danos ao } \\
\text { meio ambiente ou ao edifício }\end{array}$ & Evento prestes a ocorrer & $\begin{array}{l}\text { Evolução em } \\
\text { curto prazo }\end{array}$ \\
\hline Médio & M & 6 & $\begin{array}{l}\text { Desconfortos, deterioração do meio } \\
\text { ambiente ou do edifício }\end{array}$ & $\begin{array}{l}\text { Evento prognosticado } \\
\text { para breve }\end{array}$ & $\begin{array}{l}\text { Evolução em } \\
\text { médio prazo }\end{array}$ \\
\hline Baixo & B & 3 & $\begin{array}{c}\text { Pequenos incômodos ou pequenos } \\
\text { prejuízos financeiros }\end{array}$ & $\begin{array}{l}\text { Evento prognosticado } \\
\text { para adiante }\end{array}$ & $\begin{array}{l}\text { Evolução em } \\
\text { longo prazo }\end{array}$ \\
\hline Nenhum & $\mathrm{N}$ & 1 & Nenhuma & Evento imprevisto & $\begin{array}{l}\text { Não vai } \\
\text { evoluir }\end{array}$ \\
\hline
\end{tabular}

Após a atribuição da pontuação de todos os critérios de uma anomalia - Gravidade, Urgência E Tendência calcula-se uma nota para a anomalia, indicando sua prioridade de correção, podendo servir, também, como ordem na sequência das anomalias na Tabela GUT.

\section{Estudo de Caso: Teatro Nacional Cláudio Santoro}

O Teatro Nacional Cláudio Santoro está localizado no Setor Cultural Norte, no Eixo Monumental, definido pelo plano urbano de Lúcio Costa. É parte do Conjunto Cultual da República, projetado por Oscar Niemeyer, no qual também fazem parte a Biblioteca Nacional e o Museu da República do Setor Cultural.

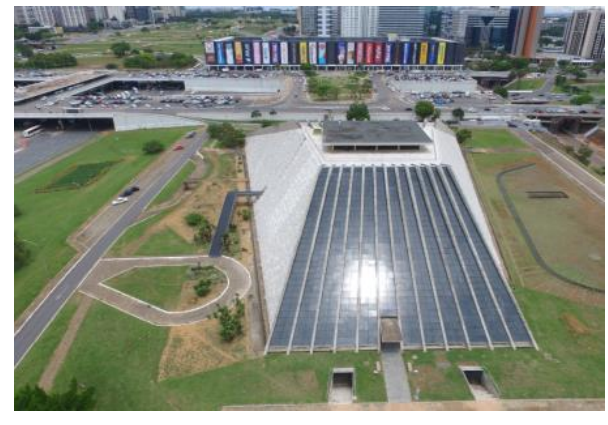

Figura 2 - Teatro Nacional Cláudio Santoro

O Teatro é integrado pelos seguintes espaços: salas Villa-Lobos (1400 lugares), Martins Pena (400 lugares) e Alberto Nepomuceno (100 lugares); galeria Athos Bulcão; Foyer das salas Villa-Lobos e Martins Pena; Mezanino da sala Villa-Lobos; Espaço Cultural Dercy Gonçalves; Anexo do Teatro Nacional (atual sede da Secretaria de Estado de Cultura do DF).

O sistema estrutural do Teatro - vigas, pilares e lajes - é todo em concreto armado e protendido. A estrutura principal é formada por quatro pilares principais (1 ao 4) que suportam toda a estrutura e recebem diretamente as cargas das vigas (A, B, C e D). As fachadas norte e sul são formadas por vigas pré-moldadas de uma única peça em forma de " $L$ ", apoiadas nas linhas $B$ e na linha $E$, escondidas pelo painel de volumes cúbicos do artista Athos Bulcão. 

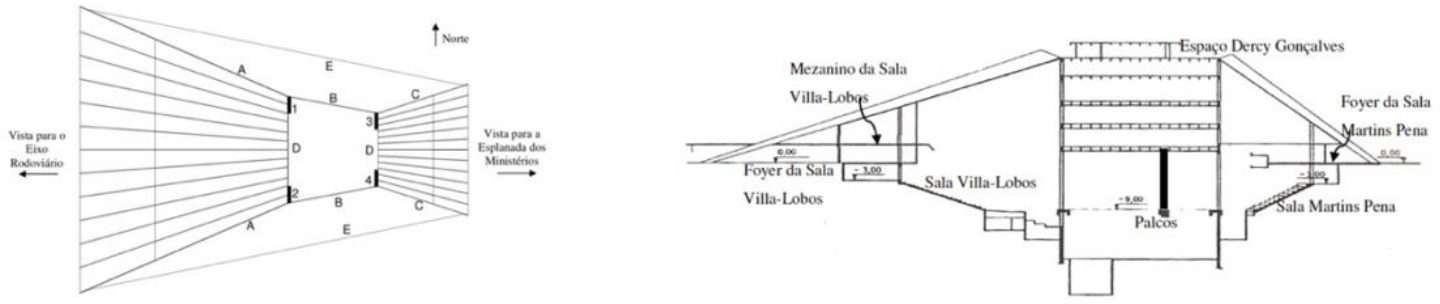

Figura 3 - Vista superior da estrutura principal do Teatro; Corte e localização dos principais espaços do Teatro -

(Souza, 2009)

\subsection{Inspeções}

Foram realizadas inspeções no Teatro Nacional Cláudio Santoro, em outubro de 2020, elaboradas pelo LabRAC da UNB, com o intuito de conhecer e informar a situação da sua estrutura, segurança e conservação do patrimônio.

Foram inspecionados 21 sistemas, mas para o presente trabalho serão analisados apenas 3: mobiliário, estrutura e cobertura.

A partir das vistorias, foram desenvolvidos relatórios e mapas de danos verificando a real qualidade de manutenção, uso e desempenho da construção, com enfoque na análise da edificação como patrimônio cultural.

Por meio da Tabela GUT foi definido o fator de degradação de cada sistema e sua prioridade de reparo e, a partir do método de Ross-Heidecke, foi verificado a depreciação do sistema pela curva de vida útil.

\subsection{1 - Mobiliário}

As poltronas das salas Villa-Lobos, Martins Pena, Alberto Nepomuceno apresentam suas estruturas internas (madeira e metálica) em excelente estado, apenas necessitando conservação. Os tecidos apresentam sujeira e esgarçamento. $O$ estofamento de espuma requer substituição, devido ao abatimento e condições de retardo ao fogo, o que também se aplica ao veludo de revestimento.

Os balcões fixos em concreto e madeira precisam de substituição dos revestimentos, lixamento e verniz na madeira.

Os armários se encontram em condições precárias e devem ser revistos.

\subsection{2 - Estrutura}

De forma geral, o sistema estrutural do Teatro apresenta uma boa condição, indicando patologias de uso, vida útil e falta de manutenção. Alguns locais pontuais merecem uma atenção especial, devido a condições mais críticas.

As principais patologias identificadas foram: degradação do concreto e armadura exposta em vigas, lajes e pilares; armaduras apresentando sinais de corrosão; fissuras; eflorescências e manchas na estrutura por vazamentos e infiltrações; juntas de dilatação sem vedação. Conforma Figuras 4, 5, 6 e7.
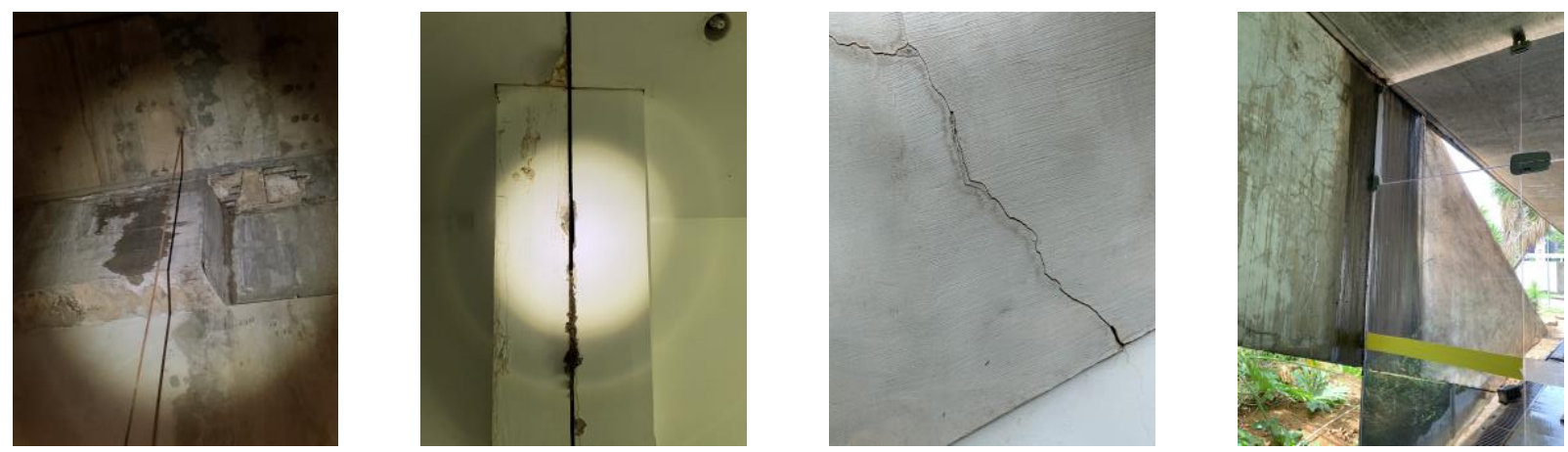

Figura 4, 5, 6 e 7 - Patologias identificadas na estrutura do Teatro Nacional 


\subsection{3 - Cobertura}

A impermeabilização da cobertura se apresenta comprometida, uma vez que há fissuras no piso e muita infiltração. A presença de vegetação contribui para o aparecimento de fissuras e danificação da impermeabilização. Há acúmulo de água no piso da cobertura, evidenciando uma queda d'água deficiente, além dos ralos apresentarem acúmulo de terra, vegetação e tampas enferrujadas, comprometendo o sistema de drenagem, verificado, também, pelo entupimento da tubulação, com fissuras e/ou problemas na vedação (vazamentos). Figuras 8, 9, 10 e 11.

As patologias encontradas na cobertura acabam por se tornarem agravantes ou precursores de outras patologias em outros sistemas, como o estrutural e o mobiliário.
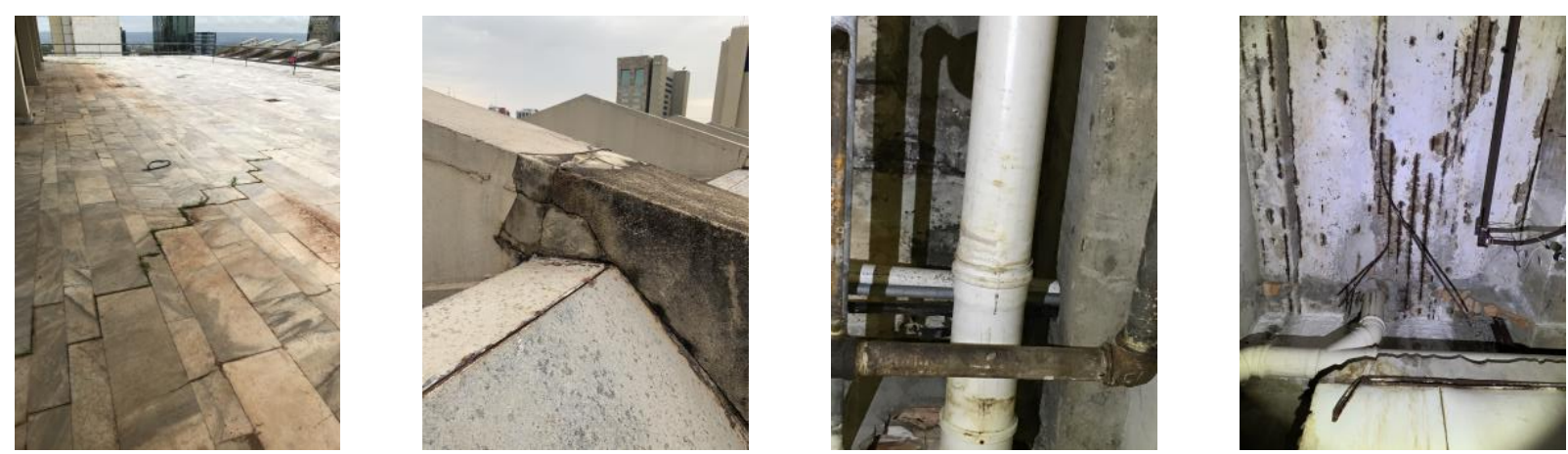

Figura 8, 9, 10 e 11 - Patologias identificadas na cobertura do Teatro Nacional

\subsection{Aplicação da Tabela GUT por metodologia adaptada}

A aplicação na Tabela GUT por metodologia adaptada se inicia após a inspeção da edificação pela divisão dos itens de degradação a serem analisados para cada elemento do sistema.

Os valores referentes a gravidade, urgência e tendência são adotados de acordo com Quadro 2.

O Fator de Degradação do Elemento $\left(F_{D E G_{e}}\right)$ é calculado pela quantidade de itens de degradação que este apresenta divido pelo total de itens analisados.

O cálculo do Fator de ponderação GUT $\left(F_{G U T}\right)$ para cada elemento do sistema é feito da seguinte forma:

$$
F_{G U T}=\frac{\text { somatória dos valor } G U T}{30 . F_{D E G_{e}}}
$$

Por fim, calcula-se o Fator de Degradação do Sistema $\left(F_{D E G}\right)$ :

$$
F_{D E G}=\frac{\text { somatória dos } F_{G U T} \text { de todos elementos }}{n^{o} \text { de elementos analisados }}
$$

O Fator de Degradação do Sistema servirá como valor de comparação entre sistemas, de forma a priorizar o reparo deste dentro do patrimônio.

\subsection{1 - Mobiliário}

De acordo com a inspeção realizada, foram considerados 4 itens de degradação: perda de elementos, falhas e desgastes, perda da autenticidade, comprometimento de uso,

Cada um desses itens foi analisado para determinado elemento do sistema mobiliário, chegando ao seguinte resultado da Tabela GUT: 
Quadro 3 - Classificação e pontuação das patologias do sistema mobiliário na Tabela GUT

\begin{tabular}{|c|c|c|c|c|c|c|}
\hline \multirow{4}{*}{ Mobiliário } & Elemento & $F_{D E G_{e}}$ & G & $\mathbf{U}$ & $\mathbf{T}$ & $F_{G U T}$ \\
\hline & Poltronas & 0,5 & $M$ & $\mathrm{~T}$ & $M$ & 0,37 \\
\hline & Balcões & 0,75 & A & $\mathrm{T}$ & $A$ & 0,65 \\
\hline & Armários & 1 & $\mathrm{~T}$ & $\mathrm{~T}$ & $\mathrm{~T}$ & 1 \\
\hline \multicolumn{7}{|c|}{$F_{D E G}=0,67$} \\
\hline
\end{tabular}

\subsection{2 - Estrutura}

De acordo com a inspeção realizada, foram considerados 10 itens de degradação: sobrecarga, deslocamentos imprevistos, apoios indevidos, armadura exposta, suportes imprevistos, baixo cobrimento da armadura, carbonatacão, eflorescência, nichos de concretagem, trincas.

Cada um desses itens foi analisado para determinado elemento do sistema estrutura, chegando ao seguinte resultado da Tabela GUT:

Quadro 4 - Classificação e pontuação das patologias do sistema estrutura na Tabela GUT

\begin{tabular}{|c|c|c|c|c|c|c|}
\hline \multirow{7}{*}{ Estrutura } & Elemento & $F_{D E G_{e}}$ & G & $\mathbf{U}$ & $\mathbf{T}$ & $F_{G U T}$ \\
\hline & Pilares de concreto & 1 & $\mathrm{~T}$ & $\mathrm{~T}$ & $\mathrm{~T}$ & 1 \\
\hline & Vigas de concreto & 1 & $\mathrm{~T}$ & $\mathrm{~T}$ & $\mathrm{~T}$ & 1 \\
\hline & Baldrames & 1 & $\mathrm{~T}$ & $\mathrm{~T}$ & $\mathrm{~T}$ & 1 \\
\hline & Alvenaria de embasamento & 1 & $\mathrm{~T}$ & $\mathrm{~T}$ & $\mathrm{~T}$ & 1 \\
\hline & Lajes & 1 & A & M & $\mathrm{N}$ & 0,5 \\
\hline & Sapatas/blocos & 0,1 & $\mathrm{~T}$ & $\mathrm{~T}$ & $\mathrm{~T}$ & 0,1 \\
\hline \multicolumn{7}{|c|}{$F_{D E G}=0,77$} \\
\hline
\end{tabular}

\subsection{3 - Cobertura}

Para o sistema cobertura foram considerados 5 itens de degradação: sobrecarga, deslocamentos imprevistos, apoios indevidos, perda de elemento; desgaste.

Cada um desses itens foi analisado para determinado elemento do sistema cobertura, chegando ao seguinte resultado da Tabela GUT:

Quadro 5 - Classificação e pontuação das patologias do sistema cobertura na Tabela GUT

\begin{tabular}{|c|c|c|c|c|c|c|}
\hline \multirow{3}{*}{ Cobertura } & Elemento & $F_{D E G_{e}}$ & G & $\mathbf{U}$ & $\mathbf{T}$ & $F_{G U T}$ \\
\hline & Estrutura de concreto & 0,8 & A & $\mathrm{T}$ & $A$ & 0,69 \\
\hline & Impermeabilização & 0,8 & A & $\mathrm{T}$ & $A$ & 0,69 \\
\hline \multicolumn{7}{|c|}{$F_{D E G}=0,69$} \\
\hline
\end{tabular}

\subsection{Depreciação dos sistemas}

Para o cálculo da curva de depreciação de um sistema, são utilizados os valores de vida útil de projeto e estado de conservação, seguindo o método de Ross-Heidecke apresentado no Item 3.

Nos sistemas aqui estudados foram considerados as seguintes vidas úteis de projeto:

- Mobiliário: 5 anos;

- Estrutura: 50 anos;

- Cobertura: 20 anos (levando em consideração a vida útil da impermeabilização). 
O gráfico de depreciação segue a mesma curva para os sistemas, alterando apenas a vida útil. Será apresentado aqui apenas o gráfico do sistema estrutura:

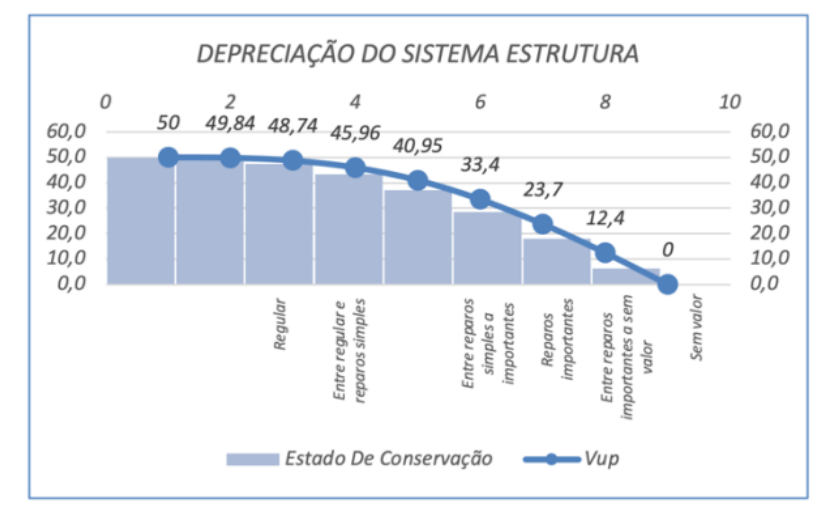

Figura 13 - Depreciação do sistema estrutura, para 50 anos

\section{Conclusões}

Este trabalho conseguiu trazer à tona, a importância de mais estudos ligados a área de conservação de patrimônios. Estes bens refletem as memórias e anseios de uma sociedade, necessitando o devido cuidado das entidades responsáveis e da população. Trazer essas análises para dentro das academias representa uma união de forças em prol de um bem comum.

No que diz respeito ao uso da Tabela GUT, nota-se a sequência de importância da recuperação do sistema estrutura, cobertura e mobiliário. Porém, quando diz respeito à um patrimônio histórico e cultural, essa ordem de prioridade não faz muito sentido. Portanto, a metodologia poderia adotar outros parâmetros de análise no contexto de patrimônio.

A curva de depreciação mostra, de forma clara, a sua relação com o estado de conservação da edificação. É, portanto, um grande desafio a manutenção dos patrimônios, que deveria ser um quesito prioritário para os gestores de toda construção, principalmente de um bem que tem relação direta com a história e economia de uma sociedade.

\section{Referências Bibliográficas}

ABNT NBR 14653-2:2011. Avaliação de bens - Parte 2: Imóveis urbanos.

ABNT NBR 14653-7:2009. Avaliação de bens - Parte 7: Bens de patrimônios históricos e artísticos.

ABNT NBR 6118:2014. Projeto de estruturas de concreto - Procedimento.

Art. 216 da Constituição Federal, Brasil. Disponível em < https://www.senado.leg.br/atividade/const/con1988/CON1988_05.10.1988/art_216_.asp> Acessado em 20/02/2021.

Gomide, T., Neto, J., Gullo, M. (2011). Inspeção Predial Total. Diretrizes e Laudos no Enfoque da Qualidade Total e da Engenharia Diagnóstica. PINI, SP, Brasil. 146 p.

Júnior, R. (2019). Introdução à Avaliação de Bens Singulares. Históricos, Culturais, Artísticos e Outros. Princípios Básicos, Fundamentos e Aplicações. São Paulo - SP, Brasil. 287 p.

Souza, D. (2009). A Estrutura do Teatro Nacional Claudio Santoro em Brasília: Histórico de Projeto, Execução, Intervenções e Estratégias para Manutenção. Dissertação de Mestrado. Faculdade de Tecnologia, Universidade de Brasília, Brasil.

Suman. (2015). Laudo Técnico de Inspeção Predial. Fórum Desembargador Hugo Auler Núcleo Bandeirante. TJDF, Brasília, Brasil. $110 \mathrm{p}$.

Portal do Iphan, Brasil. Disponível em <http://portal.iphan.gov.br>. Acesso em 20/02/2021.

Tribunal de Justiça. Anexo I - Metodologia de Depreciação. Poder Judiciário Estado do Paraná. Disponível em <http://portal.tjpr.jus.br> Acessado em 20/02/2021. 